\title{
Alterations in Endogenous Brain $\beta$-Endorphin Release by Adrenal Medullary Transplants in the Spinal Cord
}

Gal Yadid, Ph.D., Abraham Zangen, Ph.D., Uri Herzberg, D.V.M., Ph.D., R. Nakash, M.Sc., and Jacqueline Sagen, Ph.D.

While transplants of adrenal medullary cells into the spinal subarachnoid space may produce antinociception via inhibition of spinal pain transmission pathways, alterations at higher central nervous system (CNS) centers have not been addressed. Recent findings suggest that prolonged noxious stimulation results in release of endogenous $\beta$-endorphin in the brain, possibly as a compensatory mechanism to reduce nociception. The goal of this study was to determine whether adrenal medullary transplants in the spinal subarachnoid space alter endogenous

$\beta$-endorphin secretion in the hypothalamic arcuate nucleus, its principal CNS source. Pain behaviors and arcuate

$\beta$-endorphin secretion by microdialysis were monitored during the formalin pain test in animals with spinal adrenal medullary or control transplants. Basal levels of extracellular $\beta$-endorphin were 3-fold higher in adrenal medullary-implanted than in controls. In control animals, formalin induced robust pain behaviors and a marked transient increase in $\beta$-endorphin release 30-60 min following injection. In contrast, pain behaviors were attenuated and the formalin-induced increase in $\beta$-endorphin was completely blocked in adrenal medullary implanted animals. Findings from these studies indicate that adrenal medullary transplants in the spinal subarachnoid space can alter $\beta$-endorphin release in the arcuate nucleus both basally and in response to noxious stimuli. Thus, spinally placed adrenal medullary transplants not only alter local spinal cord pharmacology, but can alter endogenous neurochemistry at higher pain processing centers as well. [Neuropsychopharmacology 23:709-716, 2000] (C) 2000 American College of Neuropsychopharmacology. Published by Elsevier Science Inc.
KEY WORDS: Nociception; Analgesia; Opioid peptides; Chromaffin cells; Neural transplants; Intrathecal

Transplantation of adrenal medullary chromaffin cells in the subarachnoid space of the spinal cord has been shown to reduce pain behaviors in several animal models, including inflammatory pain (Ortega-Alvaro et al.

From the Department of Life Sciences, Bar-Ilan University, Ramat-Gan, Israel (GY, AZ, RN); Acorda Therapeutics, Hawthorn, NY (UH); and The Miami Project to Cure Paralysis, University of Miami School of Medicine, Miami, FL (JS).

Address correspondence to: Dr. Jacqueline Sagen, The Miami Project to Cure Paralysis, University of Miami School of Medicine, 1600 NW $10^{\text {th }}$ Ave. (R-48), Miami, FL 33136. 2000.
1997; Sagen et al. 1990; Siegan and Sagen 1997; Vaquero et al. 1991; Wang and Sagen 1995), neuropathic pain (Décosterd et al. 1998; Ginzburg and Seltzer 1990; Hama and Sagen 1993, 1994), and central pain models (Brewer and Yezierski 1998; Hains et al. 1998; Yu et al. 1998). This has led to the initiation of clinical trials at several centers, with promising outcomes (Buchser et al. 1996; Burgess et al., 1996; Lazorthes et al. 1995; Winnie et al. 1993). Since chromaffin cells produce and secrete several potential pain-reducing neuroactive substances, including opioid peptides and catecholamines, a possible mechanism for this pain reduction is via inhibition of spinal pain transmission pathways. In support for this, adrenal medullary transplants in the rat lumbar spinal subarachnoid space suppress flinching responses 
in the formalin pain model, an effect which is partially reversed by opioid antagonist naloxone or $\alpha$-adrenergic antagonist phentolamine (Siegan and Sagen 1997).

While local spinal actions of cellular implants have been the focus of the majority of previous studies, effects on higher central nervous system (CNS) pain processing centers have been largely ignored. In particular, recent findings by our group have demonstrated markedly increased levels of endogenous $\beta$-endorphin secretion in the hypothalamic arcuate nucleus coincident with pain behaviors in response to hindpaw injections of formalin (Zangen et al. 1998). As the arcuate nucleus is the principal source of this potent opioid peptide in the CNS (Bach 1997), this finding may be indicative of a compensatory mechanism in response to prolonged noxious stimuli. In support for this, noxious stimuli or persistent pain have been shown to increase activity in the arcuate nucleus as indicated by increased c-fos (Bullitt 1990; Pan et al. 1994), 2-deoxyglucose (Mao et al. 1993), and blood flow (Morrow et al. 2000) in that region. In addition, intense activation of spinal nociceptive pathways by intrathecal capsaicin results in increased $\beta$-endorphin release in brain lateral ventricular perfusates (Bach and Yaksh 1995a).

The hypothalamic arcuate nucleus may also play a role in endogenous analgesic responses. For example, this region is activated by analgesic low frequency electroacupuncture (Lee and Beitz 1993; Pan et al. 1994; Takeshige et al. 1992; Wang et al. 1990a,b; Zhang et al. 1996), and local stimulation of the arcuate nucleus or $\beta$-endorphin microinjection can reduce pain responses to noxious stimuli (Bach and Yaksh 1995b; Hamba 1988; Tseng and Wang 1992; Wang et al. 1990b,c). Some analgesic effects of both electroacupuncture and arcuate nucleus stimulation can be attenuated by naloxone, suggesting the involvement of endogenous opioid systems.

The goal of this study was to determine whether adrenal medullary transplants in the spinal subarachnoid space alter endogenous $\beta$-endorphin secretion, either basally or in response to noxious stimuli, in the hypothalamic arcuate nucleus. A preliminary account of these findings have been described previously (Sagen et al. 1999).

\section{MATERIALS AND METHODS}

Adult male Sprague-Dawley rats were used as both graft recipients and donors. Adrenal medullary tissue was prepared for grafting as described in detail previously (Hama and Sagen 1993). Adrenal medullary tissue from two adrenal glands was used as this has been shown previously to reduce pain behaviors in several animal models, including the formalin test (Siegan and Sagen 1997). Tissue pieces (approximately $0.5 \mathrm{~mm}^{3}$ ) were implanted into the spinal subarachnoid space of anesthetized rats (pentobarbital, $40 \mathrm{mg} / \mathrm{kg}$, i.p., supplemented as necessary) via laminectomy at L2-L3 spinal segments. Equal volumes of striated muscle from Sprague-Dawley donors were used as control grafts. Animals were immunosuppressed with Cyclosporin A $(10 \mathrm{mg} / \mathrm{kg}$, i.p.) on the day before transplantation and for three days following transplantation.

At approximately 10 days following transplantation, when graft tissue has stabilized and animals recovered from implantation procedures (Sagen et al. 1990; Siegan and Sagen 1997; Wang and Sagen 1995), animals were reanesthetized (chloral hydrate; $400 \mathrm{mg} / \mathrm{kg}$, i.p.) and microdialysis probes were stereotaxically implanted unilaterally into the arcuate nucleus $(\mathrm{P}, 2.2 . \mathrm{mm} ; \mathrm{L}, 1.0 \mathrm{~mm} ; \mathrm{H}$, $-10.0 \mathrm{~mm}$ from Bregma, at an angle of 3.5 degrees; incisor bar, -3.2). Microdialysis probes were purchased from a commercial vendor (CMA/10, $2.0 \mathrm{~mm}$ length, $20 \mathrm{kD}$ cutoff; Carnegie Mellon, Stockholm, Sweden). The in vitro $\beta$-endorphin recovery (at flow rate of $1 \mu \mathrm{l} / \mathrm{min}$ ), as determined by placing the probes in artificial cerebrospinal fluid (CSF) (aCSF; $145 \mathrm{mM} \mathrm{NaCl}, 1.2 \mathrm{mM} \mathrm{CaCl} 2,2.7 \mathrm{mM}$ $\mathrm{KCl}, 10 \mathrm{mM} \mathrm{MgCl} 2, \mathrm{pH} 7.4)$ containing $\beta$-endorphin, was $0.28 \pm 0.03 \%$, as reported previously $(n=20)$ (Zangen et al. 1998).

Sample collection was initiated in awake freely moving rats 22 to 24 hours after probe implantation. Artificial CSF was pumped continuously through the dialysis probe using a microinjection pump (CMA 100; Carnegie Mellon) at a flow rate of $1 \mu \mathrm{l} / \mathrm{min}$, as this flow rate had been determined previously to result in optimal recovery (Zangen et al. 1998). Dialysates were collected at 30-min intervals into polyethylene tubes, and immediately frozen on dry ice. To determine the concentrations of $\beta$-endorphin in the dialysates, samples were thawed and quantitated using a commercially available ELISA kit (EIAH-8843; Peninsula, Belmont, $\mathrm{CA})$. The concentrations of $\beta$-endorphin were within the linear portion of the standard curve (between 0.04 and $5.0 \mathrm{ng} / \mathrm{ml}$ ). The intra-assay variation was $4 \%$ and the inter-assay variation was 13\% (Zangen et al. 1998). The first two samples were discarded to allow for stabilization of the baseline, and the next three samples were collected and assayed to determine basal release of $\beta$-endorphin in the extracellular fluid of the arcuate nuclei in animals with adrenal medullary or striated muscle transplants in the spinal intrathecal space.

Following collection of basal release samples, animals were tested for pain responses using the formalin pain model. Formalin ( $5 \%$ in $50 \mu \mathrm{l})$ was injected subcutaneously (s.c.) unilaterally in the plantar surface of the hindpaw. This results in a biphasic flinching and biting response thought to be indicative of acute (first phase) and tonic (second phase) pain (Dubuisson and Dennis 1977). The total numbers of hindpaw flinches, licks or bites indicative of pain responses (pain score) were counted during the first 2 min following formalin injec- 
tion and during the first 2 min of each 5-min interval thereafter up to $90 \mathrm{~min}$ following formalin injection. Behavioral observations were done by an observer blinded to the transplant group. Concomitantly, microdialysis samples were collected at 30-min intervals before and following formalin injection for up to $120 \mathrm{~min}$.

At the end of behavioral testing and sample collection, animals were deeply anesthetized and perfused intracardially $(4.0 \%$ paraformaldehyde in $0.1 \mathrm{M}$ phosphate buffer), and their spinal cords and brains removed for verification of graft viability and probe placement sites, respectively. Adrenal medullary transplants were identified immunocytochemically in paraffin-embedded sections using tyrosine hydroxylase primary antisera (diluted 1:500; Incstar, Stillwater, MN) and secondary biotinylated horse anti-mouse $\operatorname{IgG}$ and an ABC Elite kit (Vector Labs, San Rafael, CA).

Statistical comparisons between transplant groups were determined using two-way ANOVA (repeated measures) and the Newman-Keuls test for multiple posthoc comparisons (SigmaStat, Jandel, Burlingame, CA).

All animal procedures were approved by the institutional animal care committee and were carried out in accordance with the Guide for Care and Use of Laboratory Animals and NIH guidelines.

\section{RESULTS}

Figure 1 shows behavioral responses to intraplantar injections of formalin. The injection of formalin in control muscle transplanted animals resulted in an initial phase of behavioral pain responses (the acute phase) during the first $5 \mathrm{~min}$ following injection. This was followed by a quiescent period and then another, more prolonged phase of pain responses (the tonic phase) at approximately 20-55 min following formalin injection. This pattern of behavioral activity was similar to that typically observed using this formalin pain model (Siegan and Sagen 1997). In contrast to muscle transplanted animals, the behavioral pain responses were significantly attenuated in animals with adrenal medullary transplants (overall $\mathrm{F}(\mathrm{df} 1,17)=14.25, p<.001$ ). Significant differences ( $p<0.05$; Newman-Keuls test) in pain scores between adrenal medullary and controltransplanted animals were observed at all time points following formalin injections except during the quiescent period between phase 1 and phase 2 (10-30 $\mathrm{min}$ post-formalin) and following resolution of pain behavioral responses ( $>70$ min post-formalin).

The effects of transplants and formalin injections on the $\beta$-endorphin release in the arcuate nucleus is shown in Figure 2. Figure 2A shows the actual levels of extracellular $\beta$-endorphin measured before and following formalin injection in transplanted animals. $\beta$-endorphin levels were overall markedly higher in adrenal medullary compared to control transplanted animals (overall $\mathrm{F}(\mathrm{df} 1,4)=7.44, p<.01$ ). The mean basal release ( \pm SEM) of $\beta$-endorphin prior to formalin in animals with either adrenal medullary transplants or control muscle transplants was calculated from the average of the three basal release samples taken before formalin injection (at "B" in Figure 2A). Basal $\beta$-endorphin extracellular levels were approximately 3-fold higher in animals with adrenal medullary transplants in the spinal subarachnoid space than in animals with control transplants $(p<.05)$. In these

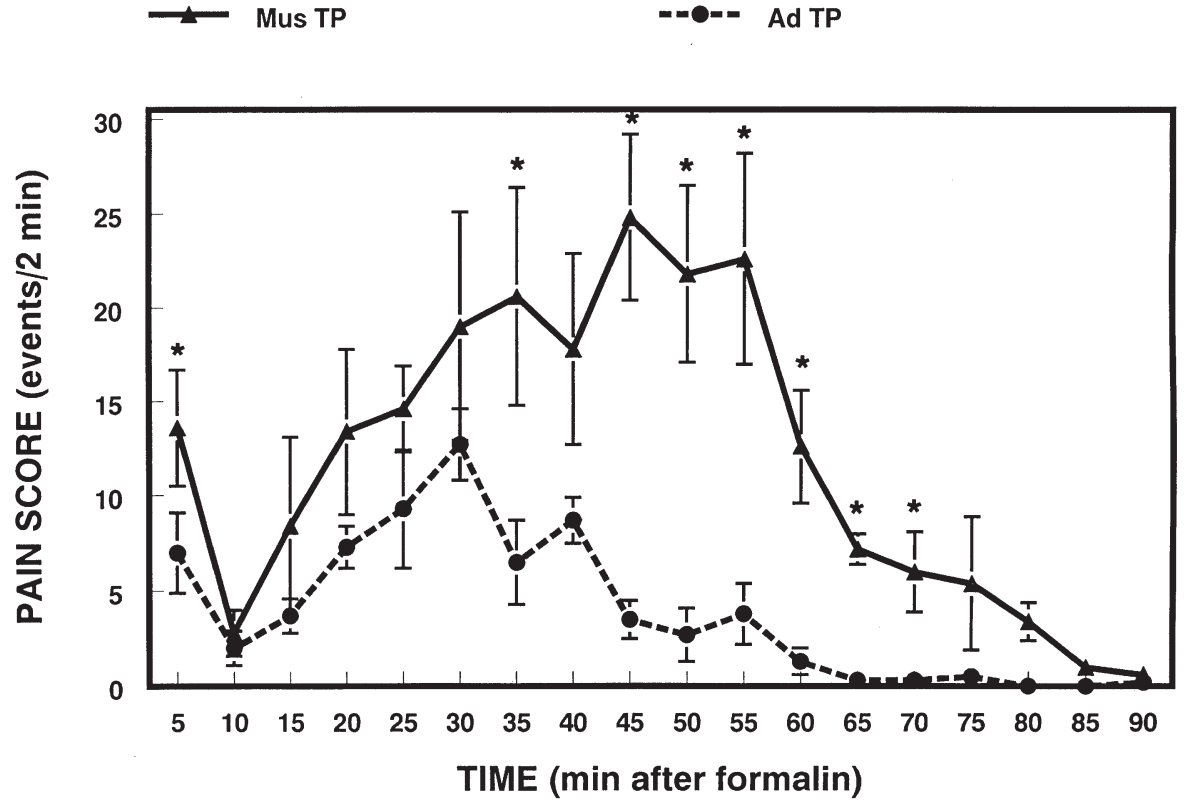

Figure 1. Time course of biphasic pain responses following formalin injection ( $5 \% ; 0.5 \mu l$, s.c.) unilaterally into the hindpaw plantar surface of animals with adrenal medullary (Ad TP; $n=6$ ) or control striated muscle (Mus TP; $n=5$ ) in the lumbar spinal subarachnoid space. Each point represents the mean \pm SEM number of pain behaviors (flinching, licking, or biting) observed per 2 min of each 5 min interval up to $90 \mathrm{~min}$ following formalin injections. Asterisks indicate $p<.05$ between transplant groups at intervals post-formalin. 
A

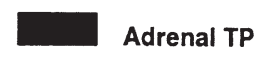

EIITA

Muscle TP

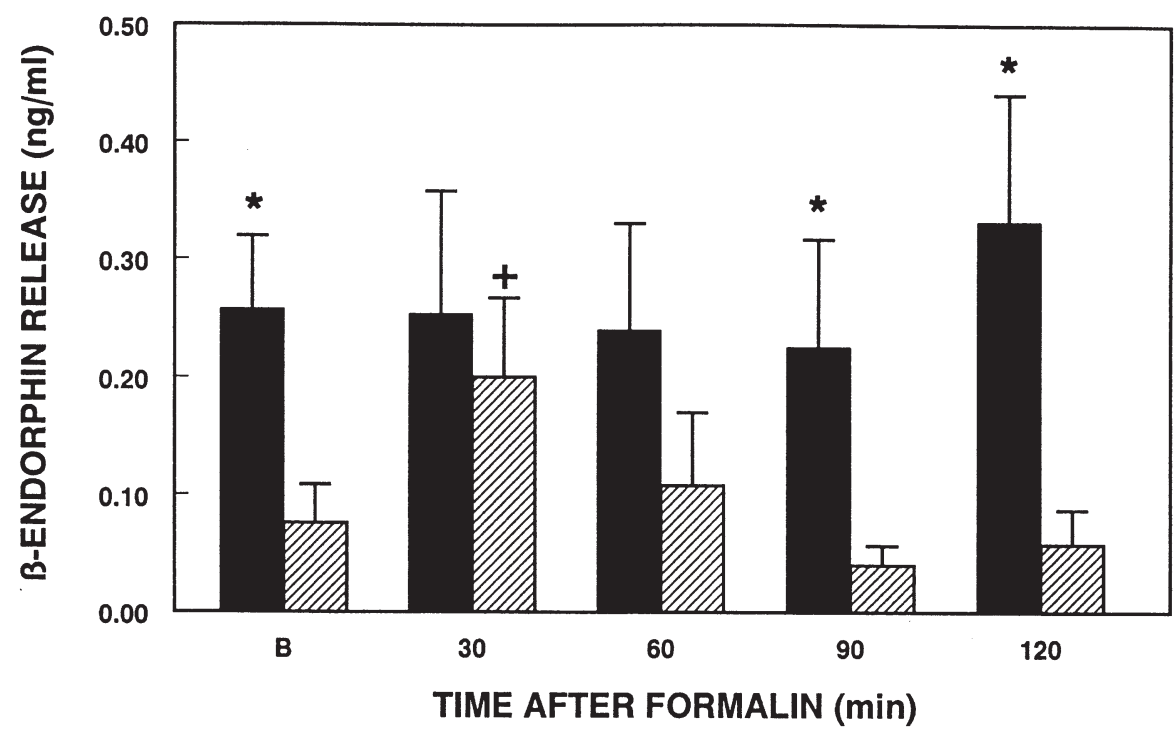

B

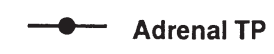

$-\star-\quad$ Muscle TP

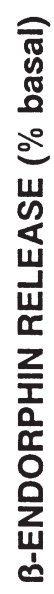

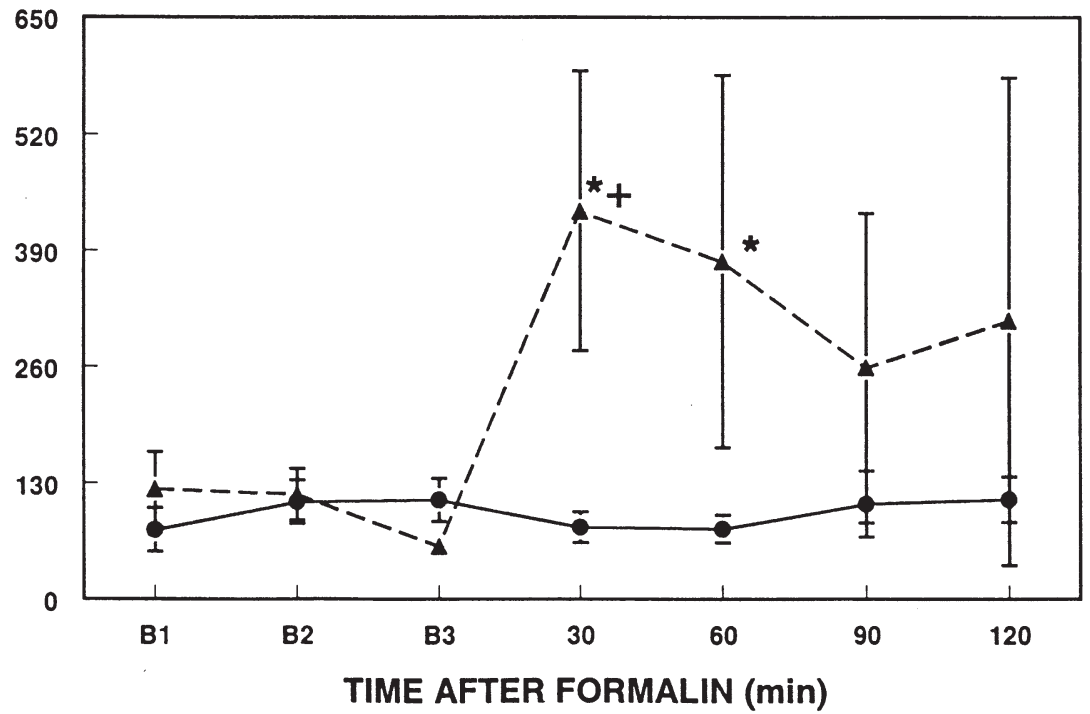

Figure 2. Effects of adrenal medullary transplants (Adrenal TP) or control striated muscle transplants (Muscle TP) on extracellular levels of $\beta$-endorphin in the hypothalamic arcuate nucleus at baseline (B) and at various intervals following intraplantar formalin injections in awake animals. (A) Raw values of $\beta$-endorphin concentrations in the dialysates (uncorrected for recovery). Basal levels in each transplant group were determined by averaging the three $30 \mathrm{~min}$ microdialysis samples collected prior to formalin injection. Additional samples were collected at $30 \mathrm{~min}$ intervals up to $120 \mathrm{~min}$ following formalin from the same animals behaviorally assessed in Figure 1. (B) $\beta$-endorphin release standardized as a percent of each animals' mean basal release prior to formalin. Three 30 min basal samples are shown (B1, $\mathrm{B} 2$, and B3), followed by four samples taken at 30,60, 90, and $120 \mathrm{~min}$ after formalin. Data is shown as mean \pm SEM. Asterisks indicate $p<$ .05 between transplant groups; + indicates $p<.05$ compared to preformalin baseline. animals, $\beta$-endorphin levels remained approximately the same during the 30-120 min course of the study following formalin injections $(p>.05$ compared to pre-formalin basal release).

In control muscle transplanted animals, the injection of formalin resulted in a transient increase in extracellular $\beta$-endorphin levels in the internal arcuate nucleus. This increase was most apparent at $30 \mathrm{~min}$ following formalin ( $p<.05$ compared to basal release), and returned to pre-formalin basal levels by $90 \mathrm{~min}$ following formalin. These findings in muscle transplanted animals are similar to those found previously in intact animals without spinal transplants (0.122 \pm $0.019 \mathrm{ng} / \mathrm{ml}$ at baseline; $0.229 \pm 0.047$ after formalin) (Zangen et al. 1998).

In order to more clearly compare dynamic changes in responses to formalin injections, the mean basal release for each individual animal was used to calculate a percent increase (or decrease) in $\beta$-endorphin following formalin (Figure 2B). This analysis revealed that 
$\beta$-endorphin secretion is markedly increased following formalin in animals with control transplants, but not in animals with adrenal medullary transplants (overall $\mathrm{F}$ $(\mathrm{df}=1,4)=7.03, P<.01)$. In animals with control transplants, $\beta$-endorphin release increased approximately 4 -fold in the internal arcuate nucleus by $30 \mathrm{~min}$ following intraplantar formalin injections $(P<.05$ compared to baselines B1, B2, and B3). This increase was apparent for approximately $60 \mathrm{~min}$ following formalin injection, and tended towards basal levels after that. This finding is consistent with formalin-evoked increases in $\beta$-endorphin levels previously reported in normal ani- mals without intraspinal transplants (Zangen et al. 1998). In contrast to control animals, formalin-evoked $\beta$-endorphin release was completely suppressed in animals with adrenal medullary transplants $(P>.05 \mathrm{com}-$ pared to baseline levels at all times following formalin).

The localization of a microdialysis probe in the hypothalamic arcuate nucleus is shown in Figure 3A. Probe localizations were confirmed at this site for the animals in this study. Figure 3B shows the appearance of a portion of adrenal medullary transplant in the rat spinal subarachnoid space. Grafted tissue lies dorsal to the host spinal parenchyma in the surrounding CSF
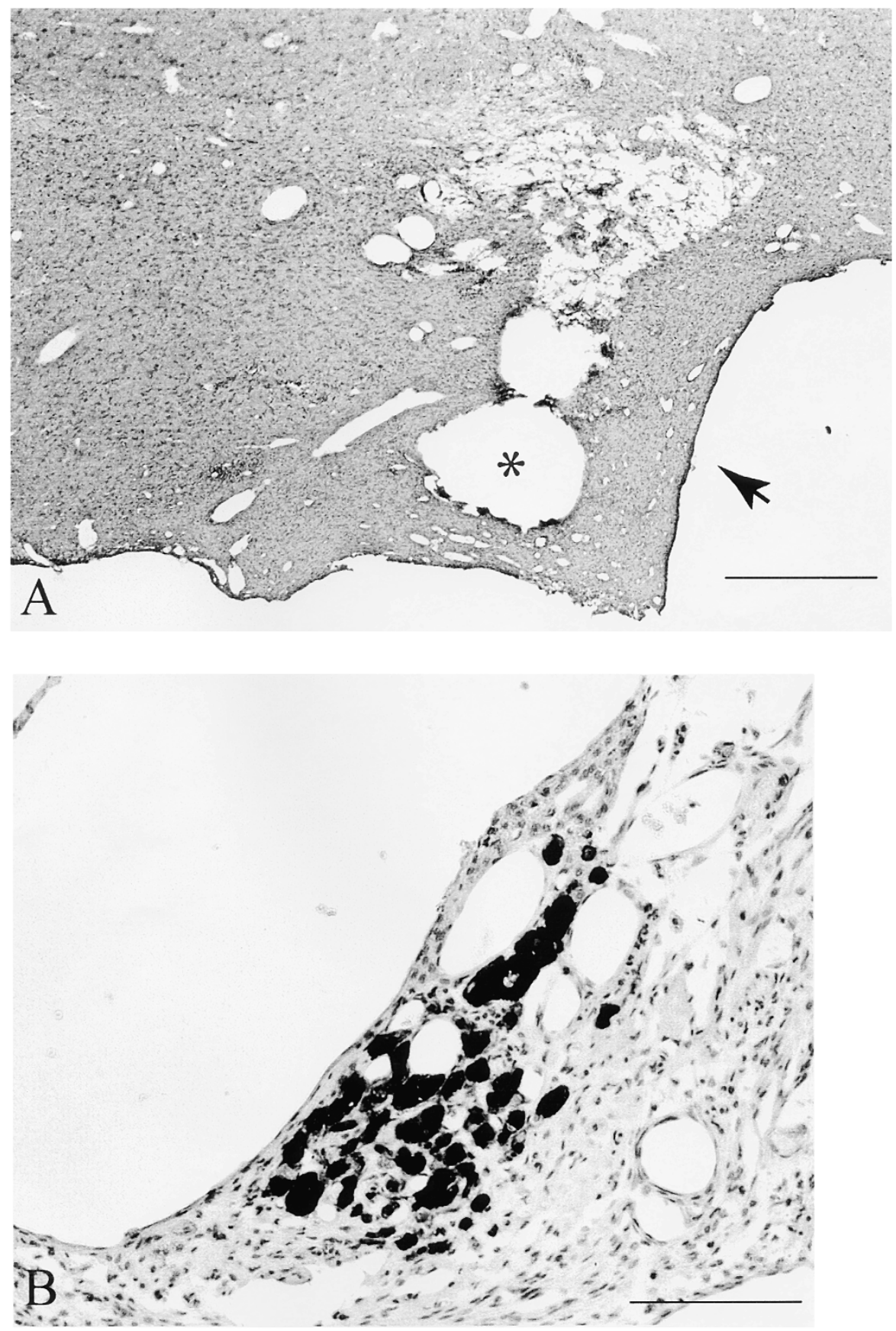

Figure 3. (A) Location of microdialysis probe in the hypothalamic arcuate nucleus. The tip of the probe is identified with an asterisk and the third ventricle is indicated at the arrow. (B) Appearance of an adrenal medullary transplant in the rat spinal subarachnoid space. Adrenal medullary chromaffin cells were identified using tyrosine hydroxylase immunocytochemistry. A cluster of tyrosine hydroxylase positive chromaffin cells is readily identified in the grafted tissue. Magnification bars $=1 \mathrm{~mm}$ (A) and $100 \mu \mathrm{m}$ (B). 
where it is generally loosely attached to either meningeal surfaces, blood vessels, or nerve roots. Healthy clusters of chromaffin cells were identified by immunocytochemical staining with tyrosine hydroxylase.

\section{DISCUSSION}

Findings from the present study demonstrate that adrenal medullary transplants in the spinal cord can markedly alter basal extracellular opioid levels and responses to noxious stimuli in the hypothalamic arcuate nucleus. In order to assess changes in endogenous brain $\beta$-endorphin secretion, a local microdialysis method was utilized which has recently been shown to accurately indicate CNS responses to noxious stimuli such as formalin (Zangen et al. 1998). The microdialysis site selected, the hypothalamic arcuate nucleus, is the primary, nearly exclusive, source of $\beta$-endorphin in the CNS, and ramifies extensively throughout the brain, with particularly dense innervation in pain modulatory regions of the periaqueductal gray and brainstem, and along the walls of the adjacent third ventricle (Bach 1997; Bloom et al. 1978; Zakarian and Smyth 1982).

Previous studies in our and other laboratories have demonstrated that transplants of adrenal medullary chromaffin cells into the subarachnoid space of the spinal cord can attenuate pain responses in a variety of animal models and offers a promising avenue for clinical pain management (Brewer and Yezierski 1998; Buchser et al. 1996; Burgess et al. 1996; Décosterd et al. 1998; Hains et al. 1998; Hama and Sagen 1993; Lazorthes et al. 1995; Ortega-Alvaro et al. 1997; Sagen et al. 1990; Siegan and Sagen 1997; Vaquero et al. 1991; Winnie et al. 1993; Yu et al. 1998). Although the transplanted cells appear to produce some of their antinociceptive effects via local release of pain-reducing analgesic agents, including catecholamines and opioid peptides, into the host spinal CSF (Sagen and Kemmler 1989; Sagen et al. 1991), recent studies have indicated that these transplants can also produce neuroplastic changes in the pain processing circuitry of the spinal cord, including restoration of spinal inhibitory neurons and decreased c-fos activation in response to persistent pain (Ibuki et al. 1997; Sagen and Wang 1995). Thus, cellular transplants in the spinal cord may result in long-term and widespread alterations in host CNS pain modulatory systems. The results of the present study provide the first evidence that such spinal transplants can produce neurochemical alterations at higher CNS levels.

The present results indicate that adrenal medullary transplants in the spinal CSF can alter $\beta$-endorphin levels in the hypothalamic arcuate nucleus in two distinctive ways: 1) increasing basal release of $\beta$-endorphin; and 2 ) attenuating $\beta$-endorphin release in response to noxious activation. In the first case, basal levels of $\beta$-endorphin were increased approximately 3 -fold in animals with spinal adrenal medullary transplants compared to control transplanted animals. While it is possible that increased $\beta$-endorphin levels were due to diffusion from the adrenal medullary cells transplanted in the spinal CSF, this is unlikely since chromaffin cells produce primarily opioid peptides derived from the proenkephalin gene, but not from the $\beta$-endorphin-producing pro-opioimelanocortin gene, and the diffusion distance would likely lead to degradation of the peptides before they reached hypothalamic sites. Thus, a more tenable explanation is that the transplanted cells have altered local spinal CNS pain transmission pathways, indirectly leading to sustained release of $\beta$-endorphin from higher centers. A possible route for these effects is the spinohypothalamic tract, which has been shown to originate in part from nociceptive neurons in the lumbar superficial dorsal horn and gray matter surrounding the central canal in rats (Burstein et al. 1987, 1990), regions previously showing neurochemical and morphological alterations following adrenal medullary transplantation (Hama and Sagen 1994; Ibuki et al. 1997; Sagen and Wang 1995).

The second effect of adrenal medullary transplants revealed in the present studies was blockade of increased $\beta$-endorphin release in response to noxious stimuli. Previous findings showed a consistent and marked transiently evoked increase in $\beta$-endorphin release from the internal arcuate nucleus, which paralleled increased pain behaviors in response to intraplantar formalin injection (Zangen et al. 1998). Similar increases in extracellular $\beta$-endorphin levels in parallel with formalin-induced flinching responses were found in control transplanted animals in the present study. Increased ventricular CSF $\beta$-endorphin levels were also reported following intense C-fiber stimulation by intrathecal capsaicin injections (Bach and Yaksh 1995a). Thus, an emergent hypothesis is that noxious stimulation may result in $\beta$-endorphin release as a compensatory means to reduce nociception.

In contrast to control animals, this compensatory increased $\beta$-endorphin release was completely blocked in animals with adrenal medullary transplants in the spinal subarachnoid space. This occurred in parallel with suppression of pain behaviors following intraplantar formalin injections. The somewhat paradoxical observation that both antinociceptive adrenal medullary transplants and nociceptive formalin injections in control animals produce increases in $\beta$-endorphin release may be explained as a CNS compensatory attempt to increase hypothalamic $\beta$-endorphin levels in response to noxious stimulation, while this has already been adjusted in animals with adrenal medullary implants. It is interesting to note that the levels of $\beta$-endorphin attained in control transplanted animals within $30 \mathrm{~min}$ following formalin injections is similar in magnitude to 
the higher basal levels already present in animals with adrenal medullary transplants. Further increases in $\beta$-endorphin secretion may either not be possible (i.e., it is at a maximum) or necessary in response to noxious challenge in adrenal medullary-transplanted animals. Similar seemingly paradoxical findings have been obtained in other laboratories, e.g., both antinociceptive electroacupuncture and noxious stimulation can produce activation of the arcuate nucleus and $\beta$-endorphin release (Pan et al. 1996), and both noxious lumbar intrathecal capsaicin injections and antinociceptive arcuate nucleus stimulation can increase $\beta$-endorphin release (Bach and Yaksh 1995a,b). Thus, changes in arcuate nucleus $\beta$-endorphin levels may reflect homeostatic changes in CNS pain responsiveness.

In summary, results from these studies demonstrate that adrenal medullary transplants in the spinal cord can increase endogenous basal $\beta$-endorphin levels and reduce compensatory increases in response to intense noxious stimuli. These findings suggest that cellular transplants in the spinal cord can affect the neurochemistry of higher CNS centers and possibly alter the overall tone of CNS pain modulatory systems.

\section{ACKNOWLEDGMENTS}

The authors thank Dr. Beata Frydel for her expertise in the immunocytochemical preparations. This work was supported by NIH grant NS25054 (JS) and The Bar Ilan Research Foundation (GY]

\section{REFERENCES}

Bach FW (1997): $\beta$-endorphin in the brain. A role in nociception. Acta Anaesthesiol Scand 41:133-140

Bach FW, Yaksh TL (1995a): Release of $\beta$-endorphin immunoreactivity into ventriculo-cisternal perfusate by lumbar intrathecal capsaicin in the rat. Brain Res 701:192-200

Bach FW, Yaksh TL (1995b): Release into ventriculo-cisternal perfusate of $\beta$-endorphin- and met-enkephalin-immunoreactivity: Effects of electrical stimulation in the arcuate nucleus and periaqueductal gray of the rat. Brain Res 690:167-176

Bloom F, Battenberg E, Rossier J, Ling N, Guillemin R (1978): Neurons containing $\beta$-endorphin in rat brain exist separately from those containing enkephalin: Immunocytochemical studies. Proc Natl Acad Sci U S A 75:15911595

Brewer KL, Yezierski RP (1998): Effects of adrenal medullary transplants on pain-related behaviors following excitotoxic spinal cord injury. Brain Res 798:83-92

Buchser E, Goddard M, Heyd B, Joseph JM, Favre J, Detribolet N, Lysaght M, Aebischer P (1996): Immunoisolated xenogeneic chromaffin cell therapy for chronic pain: Initial experience. Anesthesiology 85:1005-1012
Bullitt E (1990): Expression of c-fos-like protein as a marker for neuronal activity following noxious stimulation in the rat. J Comp Neurol 296:517-530

Burgess FW, Goddard M, Savarese D, Wilkonson H (1996): Subarachnoid bovine adrenal chromaffin cell implants for cancer pain management. Am Pain Soc Abstr 15:A33

Burstein R, Cliffer KD, Giesler GJ Jr (1987): Direct somatosensory projections from the spinal cord to the hypothalamus and telencephalon. J Neurosci 7:4159-4164

Burstein R, Cliffer KD, Giesler GJ Jr (1990): Cells of origin of the spinohypothalamic tract in the rat. J Comp Neurol 291:329-344

Décosterd I, Buchser E, Gilliard N, Saydoff J, Zurn AD, Aebischer P (1998): Intrathecal implants of bovine chromaffin cells alleviate mechanical allodynia in a rat model of neuropathic pain. Pain 76:159-166

Dubuisson D, Dennis SG (1977): The formalin test: A quantitative study of the analgesic effects of morphine, meperidine, and brain stem stimulation in rats and cats. Pain $4: 161-174$

Ginzburg R, Seltzer Z (1990): Subarachnoid spinal cord transplantation of adrenal medulla suppresses chronic neuropathic pain behavior in rats. Brain Res 523:147150

Hains BC, Chastain KM, Everhart AW, Hulsebosch CE (1998): Reduction of chronic central pain following spinal cord injury by transplants of adrenal medullary chromaffin cells. Soc Neurosci Abstr 24:1631

Hama AT, Sagen J (1993): Reduced pain-related behavior by adrenal medullary transplants in rats with experimental painful peripheral neuropathy. Pain 52:223-231

Hama AT, Sagen J (1994): Induction of a spinal NADPH-diaphorase by nerve injury is attenuated by adrenal medullary transplants. Brain Res 640:345-351

Hamba M (1988): Effects of lesion and stimulation of the rat hypothalamic arcuate nucleus on the pain system. Brain Res Bull 21:757-763

Ibuki T, Hama A, Wang X.-T, Pappas GD, Sagen J (1997): Loss of GABA-immunoreactivity in the spinal dorsal horn of rats with peripheral nerve injury and promotion of recovery by adrenal medullary grafts. Neuroscience 76:845-858

Lazorthes Y, Bès JC, Sagen J, Tafani M, Tkaczuk J, Sallerin B, Nahri I, Verdié JC, Ohayon E, Caratero C, Pappas GD (1995): Transplantation of human chromaffin cells for control of intractable cancer pain. Acta Neurochir 64:97-100

Lee JH, Beitz AJ (1993): The distribution of brain-stem and spinal cord nuclei associated with different frequencies of electroacupuncture analgesia. Pain 52:11-28

Mao J, Mayer DJ, Price DD (1993): Patterns of increased brain activity indicative of pain in a rat model of peripheral mononeuropathy. J Neurosci 13:2689-2702

Morrow TJ, Paulson PE, Brewer KL, Yezierski RP, Casey KL (2000): Chronic, selective forebrain responses to excitotoxic dorsal horn injury. Exp Neurol 161:220-226

Ortega-Alvaro A, Gibert-Rahola J, Mellado-Fernández ML, Chover AJ, Micó JA (1997): The effects of different monoaminergic antidepressants on the analgesia induced 
by spinal cord adrenal medullary transplants in the formalin test in rats. Anesth Analg 84:816-820

Pan B, Castro-Lopes JM, Coimbra A (1994): C-fos expression in the hypothalamo-pituitary system induced by electroacupuncture or noxious stimulation. Neuroreport 5:1649-1652

Pan B, Castro-Lopes JM, Coimbra A (1996): Activation of anterior lobe corticotrophs by electroacupuncture or noxious stimulation in the anaesthetized rat, as shown by co-localization of Fos protein with ACTH and $\beta$ endorphin and increased hormone release. Brain Res Bull 40:175-182

Sagen J, Herzberg U, Zangen A, Nakash R, Yadid G. (1999): Adrenal medullary transplants in the spinal cord alter noxious-evoked endogenous $\beta$-endorphin release in the brain. Int Assn Study Pain Abstr 9:156

Sagen J, Kemmler JE (1989): Increased levels of Metenkephalin-like immunoreactivity in the spinal cord CSF of rats with adrenal medullary transplants. Brain Res 502:1-10

Sagen J, Kemmler JE, Wang H (1991): Adrenal medullary transplants increase spinal cerebrospinal fluid catecholamine levels and reduce pain sensitivity. J Neurochem 56:623-627

Sagen J, Wang H (1995): Adrenal medullary grafts suppress $c$-fos induction in spinal neurons of arthritic rats. Neurosci Lett 192:181-184

Sagen J, Wang H, Pappas GD (1990): Adrenal medullary implants in rat spinal cord reduce nociception in a chronic pain model. Pain 42:69-79

Siegan JB, Sagen J (1997): Attenuation of formalin pain responses in the rat by adrenal medullary transplants in the spinal subarachnoid space. Pain 70:279-285

Takeshige C, Sato T, Mera T, Hisamitsu T, Fang J (1992): Descending pain inhibitory system involved in acupuncture analgesia. Brain Res Bull 29:617-634

Tseng LF, Wang Q (1992): Forebrain sites differentially sensitive to beta-endorphin and morphine for analgesia and release of Met-enkephalin in the pentobarbitalanesthetized rat. J Pharmacol Exp Ther 261:1028-1036

Vaquero J, Arias A, Oya S, Zurita M (1991): Chromaffin allografts into arachnoid of spinal cord reduce basal pain responses in rats. Neuroreport 2:149-151

Wang H, Sagen J (1995): Attenuation of pain-related hyperventilation in adjuvant arthritic rats with adrenal medullary transplants in the spinal subarachnoid space. Pain 63:313-320

Wang Q, Mao L, Han J (1990a): Arcuate nucleus of the hypothalamus mediates low but not high frequency electroacupunture analgesia in rats. Brain Res 513:60-66

Wang Q, Mao L, Han J (1990b): Analgesia from electrical stimulation of the hypothalamic arcuate nucleus in pentobarbital-anesthetized rats. Brain Res 526:221-227

Wang Q, Mao L, Han J (1990c): Lumbar intrathecal administration of naloxone antagonizes analgesia produced by electrical stimulation of the hypothalamic arcuate nucleus in pentobarbital-anesthetized rats. Neuropharmacology 29:1123-1129

Winnie AP, Pappas GD, Das Gupta TK, Wang H, Ortega JD, Sagen J (1993): Alleviation of cancer pain by adrenal medullary transplants in the spinal subarachnoid space: A preliminary report. Anesthesiology 79:644-653

Yu W, Hao J-X, Xu X.-J, Saydoff J, Haegerstrand A, WiesenfeldHallin Z (1998): Long-term alleviation of allodynia-like behaviors by intrathecal implantation of bovine chromaffin cells in rats with spinal cord injury. Pain 74:115-122

Zakarian S, Smyth DG (1982): Distribution of $\beta$-endorphinrelated peptide in rat pituitary and brain. Biochem J 202:561-571

Zangen A, Herzberg U, Vogel Z, Yadid B (1998): Nociceptive stimulus induces release of endogenous $\beta$-endorphin in the rat brain. Neuroscience 85:659-662

Zhang J, Wang M, He L (1996): Coexistence of Fos protein and proopiomelanocortin mRNA in hypothalamic arcuate nucleus following electroacupuncture. Acupunct Electrother Res 21:1-5 